\title{
Za den Legenden der hll. Barbara und Irene.
}

Einige kritische Bemerkungen zu den beiden Legenden, welche Albrecht Wirth in seinem Buche "Danae in christlichen Legenden" (Wien 1892; vgl. meine Besprechung Lit. Rundschau 1892, 232 ff.) in einer auch die bescheidensten Ansprüche an philologische Methode nicht erfüllenden Weise herausgegeben hat, dürften manchem Leser willkommen sein. Dieselben sind bei einer von dem Unterzeichneten und seinem Freunde Theodor Preger unternommenen Lektüre erwachsen. Von den prinzipiellen Mifsgriffen in der Verwertung der Handschriften, deren einen der Herausgeber selbst nachträglich erkannt hat, wird dabei abgesehen.

S. 105 Z. 17 ist xai zu streichen, das auch im Vallicellianus fehlt. - S. 107, 2 lies $\delta \xi \dot{v}$ statt $\delta \xi \dot{v} v$. - S. 107,66 l. $\alpha i \delta \dot{\varepsilon}$ st. oi $\delta \dot{\varepsilon}$. S. 108,72 l. $\pi \rho \circ \sigma \alpha \chi \vartheta \tilde{\eta} \nu \alpha \iota$ st. $\pi \rho \circ \sigma \alpha \lambda \vartheta \tilde{\eta} \nu \alpha \iota .-$ S. 108, 91 l. $\pi 0 i \alpha x$ -

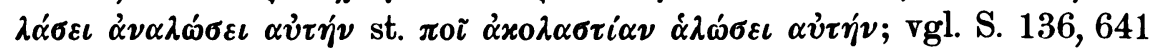

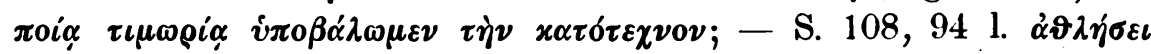
st. $\dot{\alpha} \vartheta \lambda \alpha^{\prime} \sigma \varepsilon \iota .-$ S. 117,32 l. $\pi \rho \circ \varepsilon \dot{\beta} \alpha \iota \nu \varepsilon \nu$ st. $\pi \rho \circ \varepsilon \beta \alpha i \nu \varepsilon \iota \nu$ (hoffentlich

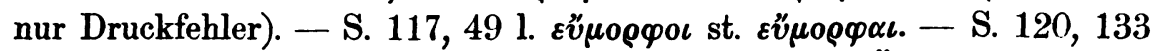
schlagen wir für das unverständliche $\delta \alpha ́ \rho o v \pi 0 \lambda v$ der Überlieferung $x \alpha-$

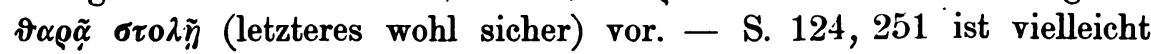

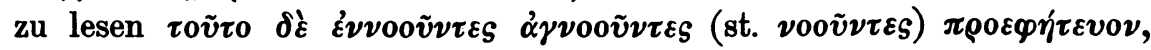

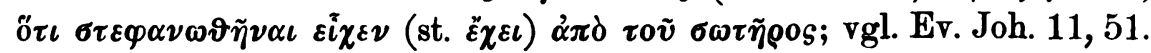

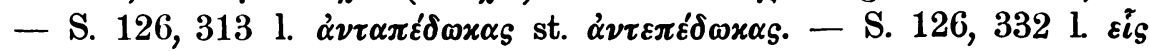

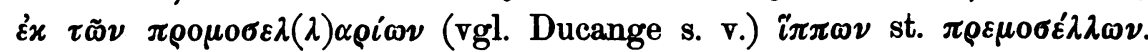

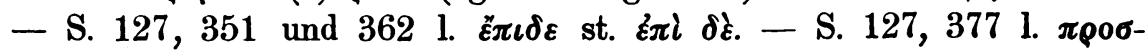

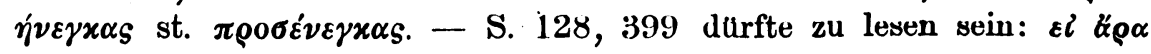

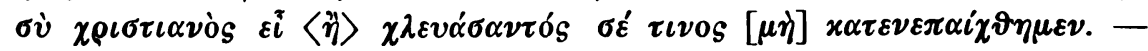

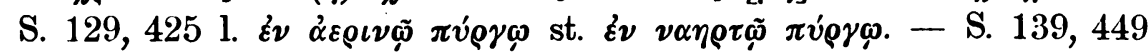

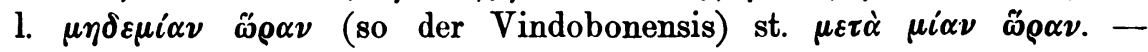

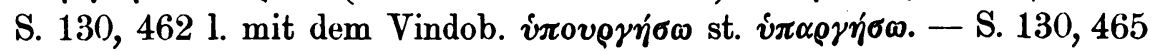

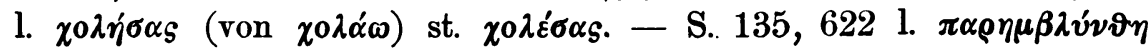

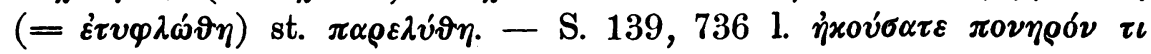

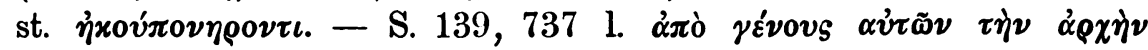
(= omnino; vgl. Joh. 8, 25 und Grimm, Lexic. gr.lat. in libros N. T.

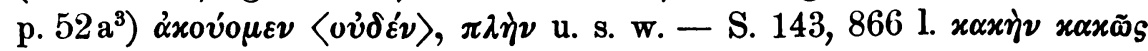

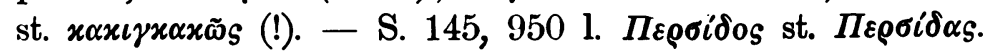

München.

Carl Weyman. 